Max-Planck-Institut für demografische Forschung

Max Planck Institute for Demographic Research

Konrad-Zuse-Strasse 1 - D-18057 Rostock - GERMANY

Tel +49 (0) 3812081 - 0; Fax +49 (0) 3812081 - 202;

http://www.demogr.mpg.de

MPIDR TECHNICAL REPORT 2011-002

FEBRUARY 2011

\title{
Order-Specific Fertility Estimates based on Perinatal Statistics and Statistics on Out-Of-Hospital Births
}

\author{
Michaela Kreyenfeld (kreyenfeld@demogr.mpg.de) \\ Frederik Peters (peters@demogr.mpg.de) \\ Rembrandt Scholz (scholz@demogr.mpg.de) \\ Ines Wlosnewski (ines.wlosnewski@uniklinik-freiburg.de)
}

This technical report has been approved for release by: Vladimir Shkolnikov (shkolnikov@demogr.mpg.de), Head of the Laboratory of Demographic Data.

(C) Copyright is held by the authors.

Technical reports of the Max Planck Institute for Demographic Research receive only limited review. Views or opinions expressed in technical reports are attributable to the authors and do not necessarily reflect those of the Institute. 


\title{
Technical Background \\ Order-Specific Fertility Estimates based on Perinatal Statistics and Statistics on Out-Of-Hospital Births
}

\author{
Michaela Kreyenfeld (kreyenfeld@demogr.mpg.de) \\ Frederik Peters (peters@demogr.mpg.de) \\ Rembrandt Scholz (scholz@demogr.mpg.de) \\ Ines Wlosnewski (ines.wlosnewski@uniklinik-freiburg.de)
}

\begin{abstract}
Until 2008, German vital statistics has not provided information on biological birth order. We have tried to close part of this gap by providing order-specific fertility rates generated from Perinatal Statistics and statistics on out-of-hospital births for the period 2001-2008. This investigation has been published in Comparative Population Studies (CPoS) (see Kreyenfeld, Scholz, Peters and Wlosnewski 2010). The CPoS-paper describes how data from the Perinatal Statistics and statistics on out-of-hospital births can be used to estimate order-specific fertility rates. The main purpose of this Technical Report is to make available the original birth counts, which were used in the study published in CPoS. Furthermore, we provide additional background information on the data sources in this report.
\end{abstract}

Keywords: Birth order, fertility, Germany, Eastern and Western Germany, Perinatal Statistics 


\section{Introduction}

Until 2008, German vital statistics has not provided information on biological birth order. We have tried to close part of this gap by providing order-specific fertility rates generated from Perinatal Statistics and statistics on out-of-hospital births for the period 2001-2008. This study has been published in Comparative Population Studies (CPoS) (see Kreyenfeld, Scholz, Peters and Wlosnewski 2010). The CPoS-paper describes how data from the Perinatal Statistics and statistics on out-of-hospital births was used to estimate order-specific fertility rates. The main purpose of this Technical Report is to make available the original birth counts from the CPoS-paper. In the following, we describe the two data sources that the study was based on: the Perinatal Statistics and the statistics on out-of-hospital births. The latter is abbreviated with "QUAG Statistics" as it has been provided by the "Gesellschaft für die Qualität in der außerklinischen Geburtshilfe e.V.” (QUAG, English: Association for Quality in Out-of-Hospital Births). In the second part of this paper, we discuss some peculiarities of the two data sets and the strategy how we dealt with unclear or missing cases. Finally, we describe the method that was applied to estimate the birth counts. This report is also accompanied by Excel files that contain the birth counts that we have generated (see Table 1 for an overview on the content of the Excel sheets).

Table 1: Content of the two Excel files enclosed to this report.

\begin{tabular}{|c|c|c|}
\hline File & Worksheet Name & Content \\
\hline \multirow[t]{4}{*}{ PERINATAL.xls } & DEU & $\begin{array}{l}\text { Number of births by age and order, estimates based on } \\
\text { Perinatal Statistics, Germany }\end{array}$ \\
\hline & DEU_EAST & $\begin{array}{l}\text { Number of births by age and order, estimates based on } \\
\text { Perinatal Statistics, Eastern Germany }\end{array}$ \\
\hline & DEU_WEST & $\begin{array}{l}\text { Number of births by age and order, estimates based on } \\
\text { Perinatal Statistics, Western Germany }\end{array}$ \\
\hline & Weights & Weights, method 1 (only Perinatal Statistics) \\
\hline \multirow[t]{4}{*}{ PERINATAL_QUAG.xls } & DEU & $\begin{array}{l}\text { Number of births by age and order, estimates based on } \\
\text { Perinatal Statistics and QUAG Statistics, Germany }\end{array}$ \\
\hline & DEU_EAST & $\begin{array}{l}\text { Number of births by age and order, estimates based on } \\
\text { Perinatal Statistics and QUAG Statistics, Eastern Germany }\end{array}$ \\
\hline & DEU_WEST & $\begin{array}{l}\text { Number of births by age and order, estimates based on } \\
\text { Perinatal Statistics and QUAG Statistics, Western Germany }\end{array}$ \\
\hline & Weights & $\begin{array}{l}\text { Weights, method } 2 \text { (only Perinatal Statistics and QUAG } \\
\text { Statistics) }\end{array}$ \\
\hline
\end{tabular}




\section{Data}

The study draws on two types of data: Firstly, we use Perinatal Statistics that includes hospital births. Secondly, we have used data on out-of-hospital births which have been provided by the “Gesellschaft für die Qualität in der außerklinischen Geburtshilfe e.V.” (QUAG). Both data sets are described in the following.

\subsection{The Perinatal Statistics}

The Perinatal Statistics used to be maintained by the Bundesgeschäftsstelle Qualitätssicherung (BQS, English: Institute for Quality and Safety) which provided us with the data. However, responsibilities have recently shifted and now the Aqua-Institut is responsible for administering this data (see http://www.aqua-institut.de). Data for the Perinatal Statistics are collected by the staff of the hospital where the woman delivers the child based on the pregnancy record (Mutterpass) of the mother and by asking the mother to provide certain information (such as smoking habits). The characteristics of a newborn, such as weight, sex and physical condition, are taken from the medical records of the child. As a result, the Perinatal Statistics provides a rich set of variables for micro-level medical and demographic research. ${ }^{1}$ Especially the following variables might be useful for addressing interesting research questions:

- $\quad$ age of mother

- pregnancy history (numbers of live births, still births, abortions, terminations of pregnancy $)^{2}$

- $\quad$ partnership status (whether woman has a steady partner)

- country of birth (however, the current citizenship is not surveyed)

- $\quad$ smoking habits during pregnancy ${ }^{3}$

- physical measurements such as body mass index of mother and child (for mother: weight at first medical examination and at birth)

- various indicators reflecting results of medical checkups during pregnancy and after childbirth

\footnotetext{
$1 \quad$ See Appendix for extract from the questionnaire

2 Unfortunately, information on the dates of previous pregnancies and births are not collected.

3 Defined as cigarettes per day, many missing cases, no information on smoking career.
} 
- detailed information about complications during pregnancy, congenital abnormalities and infant morbidity as well as mortality

Some shortcomings of the Perinatal Statistics should be mentioned. Most important, the Perinatal Statistics does not include deliveries that take place at home, in birth centers, or in the offices of midwives. The share of these out-of-hospital deliveries is only about two percent (see Table 2). However, the fact that these births are not included in the Perinatal Statistics is a potential problem because women who opt for an out-of-hospital birth differ in several ways from other women. Out-of-hospital births are more likely to be chosen by older women and those who have already one or two prior children (Loytved and Wenzlaff 2007).

Another problem of the Perinatal Statistics is that data quality was increasing with time. Although it is mandatory for all hospitals to provide information on all births since 2001, not all hospital births and not all German federal states were covered in the early years.

This can be seen from Table 2 which displays the total number of births in our sample and compares it with complete data from the vital statistics. The differences between the vital statistics and the Perinatal Statistics are large in 2001 and 2002, but they decline over the years. The low coverage in the year 2001 can mainly be attributed to the fact that in this year three German Federal States, Hesse, Schleswig-Holstein and Saarland, did not deliver their data.

Table 2: Coverage of Births in the Perinatal Statistics

\begin{tabular}{|l|r|r|r|r|r|r|r|r|}
\hline & $\mathbf{2 0 0 1}$ & $\mathbf{2 0 0 2}$ & $\mathbf{2 0 0 3}$ & $\mathbf{2 0 0 4}$ & $\mathbf{2 0 0 5}$ & $\mathbf{2 0 0 6}$ & $\mathbf{2 0 0 7}$ & $\mathbf{2 0 0 8}$ \\
\hline Births in & 452,826 & 608,122 & 590,293 & 671,228 & 665,718 & 655,951 & 667,016 & 667,227 \\
Perinatal Statistics & 734,475 & 719,250 & 706,721 & 705,622 & 685,795 & 672,724 & 684,862 & 682,514 \\
\hline $\begin{array}{l}\text { Births in } \\
\text { Vital Statistics }\end{array}$ & 0.62 & 0.85 & 0.84 & 0.95 & 0.97 & 0.98 & 0.97 & 0.98 \\
\hline $\begin{array}{l}\text { Perinatal Statistics/ } \\
\text { Vital Statistics }\end{array}$ & & & & & & & & \\
\hline
\end{tabular}

Source: Kreyenfeld, Scholz, Peters and Wlosnewski 2010

\subsection{The Statistics on Out-Of-Hospital Births}

The second type of data we are using is the statistics on out-of-hospital births. This statistics is monitored by the "Gesellschaft für die Qualität in der außerklinischen Geburtshilfe e.V." (QUAG, English: Association for Quality in Out-of-Hospital Births). We have abbreviated this statistics with QUAG Statistics. A questionnaire similar to the one used in collecting the 
Perinatal Statistics is used. ${ }^{4}$ Although participation of midwives is voluntary, about 80 percent of all out-of-hospital births are covered in this data source (Loytved 2009: 6). Because the structure of the variables in the QUAG Statistics is almost the same as in the Perinatal Statistics the two sources can be combined in a straightforward manner.

An essential measure of quality for the QUAG Statistics is how many of all out-of-hospital births are included in the data set. Table 3 compares the number of births in the QUAG Statistics with the calculated total number of out-of-hospital births in Germany. ${ }^{5}$ As can be seen from this table, coverage of the out-of-hospital births in the QUAG Statistics ranges from 68 to 91 percent. This is lower than the coverage of the Perinatal Statistics. However, we assume that non-response is distributed randomly, so that this statistics will provide us with reasonable estimates of the age and parity distribution of out-of-hospital births.

Table 3: Coverage of Births in QUAG Statistics

\begin{tabular}{|l|c|c|c|c|c|c|c|c|}
\hline & $\mathbf{2 0 0 1}$ & $\mathbf{2 0 0 2}$ & $\mathbf{2 0 0 3}$ & $\mathbf{2 0 0 4}$ & $\mathbf{2 0 0 5}$ & $\mathbf{2 0 0 6}$ & $\mathbf{2 0 0 7}$ & $\mathbf{2 0 0 8}$ \\
\hline $\begin{array}{l}\text { Number of births in } \\
\text { QUAG Statistics }\end{array}$ & 8,245 & 8,219 & 8,561 & 8,686 & 8,305 & 8,315 & 8,188 & 8,280 \\
\hline $\begin{array}{l}\text { Out-of-hospital births } \\
\text { in Germany }\end{array}$ & 9,841 & 11,236 & 9,415 & 12,130 & 12,260 & 10,859 & 10,997 & 9,799 \\
\hline $\begin{array}{l}\text { Number of births } \\
\text { in Germany }\end{array}$ & 734,475 & 719,250 & 706,721 & 705,622 & 685,795 & 672,724 & 684,862 & 682,514 \\
\hline $\begin{array}{l}\text { Coverage of out-of-hospital } \\
\text { births in QUAG Statistics }\end{array}$ & $84 \%$ & $73 \%$ & $91 \%$ & $72 \%$ & $68 \%$ & $77 \%$ & $74 \%$ & $84 \%$ \\
\hline $\begin{array}{l}\text { Share of out-of-hospital births } \\
\text { out of all births in Germany }\end{array}$ & $1 \%$ & $2 \%$ & $1 \%$ & $2 \%$ & $2 \%$ & $2 \%$ & $2 \%$ & $1 \%$ \\
\hline
\end{tabular}

Notes: *) The number of out-of-hospital births was generated as the difference between the number of births in the vital statistics and the number of hospital births taken from the Gesundheitsberichterstattung des Bundes (Statistisches Bundesamt 2009b).

Source: Kreyenfeld, Scholz, Peters and Wlosnewski 2010

4 Unfortunately, information on the dates of previous pregnancies and births are not collected.

5 Unfortunately, there are no official records on the total number of out-of-hospital births in Germany. They can neither be generated from the Perinatal Statistics as this statistics is not complete during the first years after the central register had been established. The data in Table 2 comes from the „Gesundheitsberichterstattung des Bundes“ (Statistisches Bundesamt 2009). We should note, however, that this is probably the upper benchmark for the actual amount of out-of-hospital births (Loytved 2009: 6). 


\subsection{Definition of Variables}

Since the QUAG and the Perinatal Statistics are rather similar, all variables that we require for our investigation are available in both data sets. The following variables have been used:

Age at birth was defined as the difference between year of birth of mother and year of birth of the child (also known as "age reached during the year").

Regional aspects were taken into account by distinguishing Eastern Germany and Western Germany. Eastern Germany is here defined as Eastern Germany including the entire city of Berlin. Western Germany does not include Berlin. ${ }^{6}$

The order of a birth was constructed by adding one to the number of prior live births. One aspect that required special attention concerns the multiple births. For singletons, the birth order can be generated by simply adding a one to the number of previously live-born children. This strategy needed to be modified for multiple births, because the numbers of previously born children do not take into account the current birth. In other words, if a woman gives birth to twins and does not have any prior children, the number of previous live births is zero in the Perinatal Statistics. If we would apply the same strategy as for singletons, we would assign erroneously both children the birth order one. We corrected this bias by assigning one of the twins to birth order one, while the other one corresponds to birth order two. ${ }^{7}$

\subsection{Excluded births}

Only a small number of births had to be omitted from the raw data in both data sets (see Table 4). This pertains to births with missing information on the year of birth of the child. We also deleted cases where the mother's age at childbirth was below age 11 or above age 50 as we assumed that these cases were mostly miscoding. Furthermore, in the QUAG Statistics, there were also some cases with missing information, either on the number of prior live-born children or on the age of the mother, which were omitted, too. ${ }^{8}$ In total, we deleted 0.09

We do not provide any estimates by federal land. The reason is that we require the number of births from the vital statistics to generate the weighting factor. However, there is a disagreement between the vital and the Perinatal Statistics in reporting births by region. In the vital statistics the births are assigned according to the place of residence of the mother. In the Perinatal Statistics, births are assigned according to the place of birth of the child. There are some women who might not give birth in the same federal state as they are living in. This particularly applies to women in Brandenburg who frequently choose to give birth in a hospital in Berlin.

7 We first generated a master table that contained the number of all children by order, age and region. Then, we generated a 'multiple birth table' that contained multiple births by order, age and region. Finally, from the master table, we subtracted half of all multiple births of a given order. These children were then added to the counts of the next birth order. For simplicity, we assumed that all multiple births are twin births.

8 The Perinatal Statistics contained several cases with missing information on prior live births. These were all, according to information from the BQS, nulliparous women. We conducted some consistency checks in which we took into account information on the pregnancy history of the women. This consistency 
percent of the cases of the raw data of the Perinatal Statistics. In the QUAG Statistics, the number of omitted cases from the raw data is, with 7 percent, however, substantially higher.

We used this data to check how well the Perinatal Statistics and the QUAG Statistics cover all hospital and out-of hospital births in Germany (see Table 2 and Table 3). However, when we tried to generate weights we ran into a problem. For generating weights (see below), we required the birth counts from the German Statistical Office. At the time when we wrote this paper, we only had access to birth counts by single ages for the age range 15-44. The births for the ages below 15 and above 45 were provided in terms of open intervals ("below age 15" and "above age 45"). As we were unsure how to generate weights for the open intervals, we decided to omit these ages from the further analysis. We therefore, reduced the sample further and only considered women ages 15-44.

Table 4: Number of Live-Born Children 2001-2008 in Perinatal and QUAG Statistics

\begin{tabular}{|l|l|l|}
\hline & Perinatal Statistics & QUAG Statistics \\
\hline Live-born children in raw file & $4,982,707$ & 71,963 \\
Deleted cases & 4,326 & 5,234 \\
Remaining sample (ages 11-50) & $4,978,381$ & 66,729 \\
Remaining sample (ages 15-44) & $4,970,422$ & 66,640 \\
\hline
\end{tabular}

Source: BQS Perinatal Statistics and QUAG Statistics (own calculations)

\section{Method}

Our main goal has been to use the Perinatal Statistics to generate the number of births by order and age for Germany and separately for its eastern and western parts. We seek to provide estimates that match the total number of births in Germany, e.g. to calculate birth rates at population level. For this reason, we generated a weighting factor that re-weights the births from the Perinatal Statistics in a way that they match the total number of births in Germany. ${ }^{9}$ We provided two sets of estimates. The first one uses only data from the Perinatal Statistics (section 4.1). In addition to that, the second approach relies on data from both the Perinatal Statistics and the QUAG Statistics (section 4.2).

check buttressed the assumption that cases with missing information on prior live births were childless women.

9 We use the same weight for each birth order. 


\subsection{Estimation based on Perinatal Statistics}

We have constructed a weighting factor that considers age, year and region (eastern and western Germany). Let $B^{V}$ be the number of births in the vital statistics, $B^{P}$ be the number of births in the Perinatal Statistics, and $w$ be the weight. The weight accounts for age (a), year $(t)$ and region $(r)$. It is calculated as the ratio of the number of births in the vital statistics to the number of births in the Perinatal Statistics:

$$
w(a, t, r)=\frac{B^{V}(a, t, r)}{B^{p}(a, t, r)}
$$

Then, the numbers of order-specific births from the Perinatal Statistics $B_{i}^{P}$ (where $i$ denotes the order of the births) are multiplied by these weights. This gives the estimated number of order-specific births by age, year and region, that is based on the Perinatal Statistics.

$\hat{B}_{i}(a, t, r)=B_{i}^{P}(a, t, r) \times w(a, t, r)$

\subsection{Estimation based on both Perinatal and QUAG Statistics}

We constructed an additional weighting factor which also accounts for the births in the QUAG Statistics. Let $B^{V}$ be the number of births in the vital statistics, $B^{Q}$ be the number of births in the QUAG Statistics, $B^{P}$ be the number of births in the Perinatal Statistics, $i$ be the order of the births, and $w^{*}$ be the new weighting factor. The weight again accounts for age $(a)$, year $(t)$ and region $(r)$. It is generated by dividing the number of births from the vital statistics, by the sum of the number of births in the Perinatal and the QUAG Statistics:

$w^{*}(a, t, r)=\frac{B^{\vee}(a, t, r)}{B^{P}(a, t, r)+B^{Q}(a, t, r)}$

In the next step, the number of order-specific births $B_{i}$ by age $(a)$, year $(t)$ and region $(r)$ from the Perinatal and the QUAG Statistics are multiplied by the new weights to obtain the estimated number of births:

$\hat{B}_{i}^{*}(a, t, r)=\left[B_{i}^{P}(a, t, r)+B_{i}^{Q}(a, t, r)\right] \times w^{*}(a, t, r)$ 


\section{Conclusion}

The main purpose of this Technical Report was to provide more detailed technical information related to the paper "Order-Specific Fertility Rates for Germany: Estimates from Perinatal Statistics for the Period 2001-2008” that was published in Comparative Population Studies in 2010. This Technical Report also includes two Excel files that provide the birth counts for the estimation of order-specific fertility rates. The first file contains the orderspecific birth counts based on estimation with the Perinatal Statistics only (Method 1). The second file provides the order-specific birth counts that additionally take into account out-ofhospital births (Method 2). Both files also include the weights that were applied.

The two sets provide very similar birth counts by age of mother. This confirms that the estimates from Method 1 are robust. From this, we concluded that the inclusion of out-ofhospital births does not affect the results (see Kreyenfeld, Scholz, Peters and Wlosnewski 2010). This might be relevant for future analyses in which researchers might use the Perinatal Statistics to generate order-specific fertility rates for the time before 2001 or after 2008. 


\section{References}

Bundesgeschäftsstelle Qualitätssicherung (2009): Fragebogen Datensatz Geburtshilfe. http://www.bqs-online.com/download/boegen-2009/16-1.pdf (Download, 16-02-2009)

Kreyenfeld, Michaela/ Scholz, Rembrandt/ Peters, Frederik/ Wlosnewski, Ines (2010): OrderSpecific Fertility Rates for Germany: Estimates from Perinatal Statistics for the Period 20012008. Comparative Population Studies 35 (Zeitschrift für Bevölkerungswissenschaft): 207224.

http://wWw. comparativepopulationstudies.de/index.php/CPoS/article/view/31/2 2 .

Loytved, Christine (2009): Qualitätsbericht 2006. Außerklinische Geburtshilfe in Deutschland. Im Auftrag der „Gesellschaft für Qualität in der außerklinischen Geburtshilfe e.V.“. URL: http://www.quag.de/downloads/QUAG_bericht2006.pdf, 28.10.2010.

Loytved, Christine/ Wenzlaff, Paul (2007): Außerklinische Geburt in Deutschland. German Out-Of-Hospital Birth Study 2000-2004. Bern: Huber.

Loytved, C. (2009): Qualitätsbericht 2007. Außerklinische Geburtshilfe in Deutschland. Im Auftrag der „Gesellschaft für Qualität in der außerklinischen Geburtshilfe e.V.“ http://www.quag.de/downloads/QUAG_bericht2007.pdf (Download, 19-01-2010).

Statistisches Bundesamt (2009): Entbindungen und Geburten im Krankenhaus nach Ländern. (Excel Sheets provided upon correspondence to Ute Bölt (Statistisches Bundesamt), 30-102009. 


\section{Appendix}

Figure 1: Extract from the Perinatal Statistics form

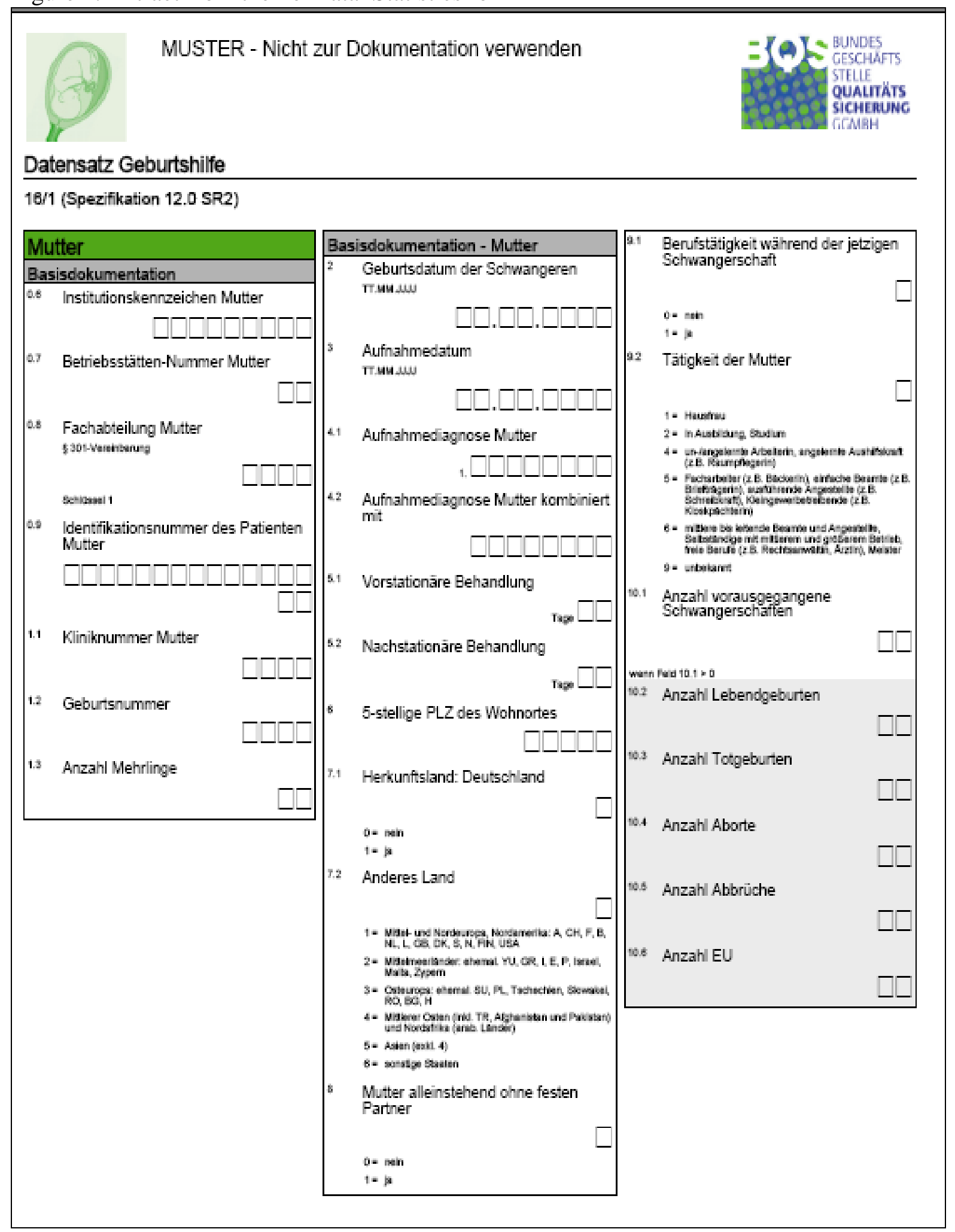




\section{Notes to Figure 1:}

The questionnaire documents characteristics of the mother. It asks for several identification numbers of mother and birth (0.5 to 1.2), the number of multiples (1.3), date of birth of the mother, date of accommodation in hospital, diagnosis at accommodation and treatments (2 to 5), country of origin of mother (5 to 7), partnership status of mother (8), employment (9) and number of preceding pregnancies plus number of live-births, stillbirths, aborts and terminations of pregnancy (10).

Source: Bundesgeschäftsstelle Qualitätssicherung (2009). 
Figure 2: Questionnaire QUAG Statistics

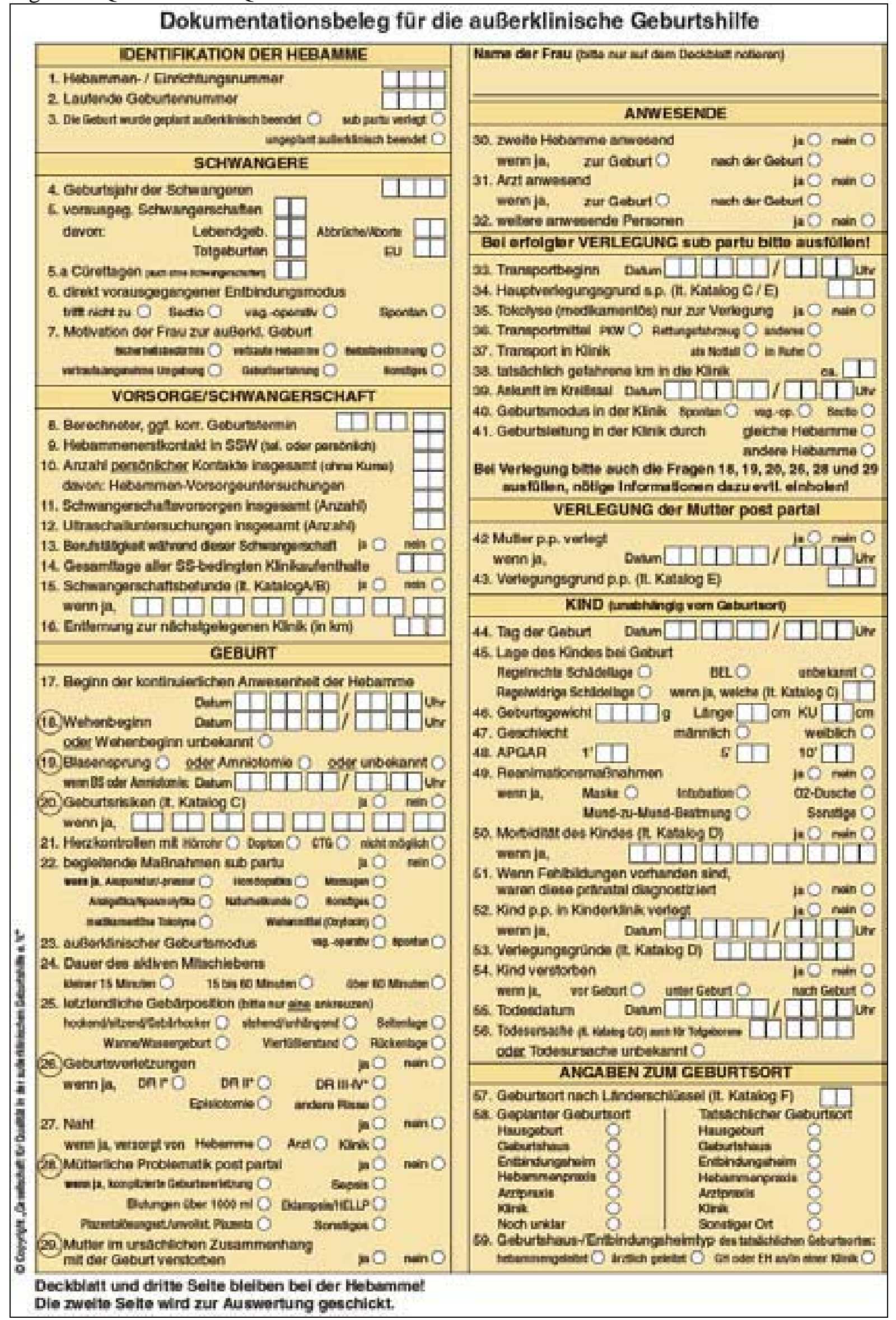


Notes to Figure 2:

This questionnaire provides detailed information about the procedure on births out-ofhospitals. It offers for identification of the midwife (1 to 3), information about the pregnant women such as number of preceding pregnancies, number of live-births, stillbirths, abortions/ terminations of pregnancy (4 to 7), characteristics of the pregnancy and preventive check-ups (8-16), the progress of birth (17-29), attendees during the birth (30-32), possible transferring of mother to hospital (33-43), characteristics of the child like date of birth, sex, weight and health status (44-56) and place of birth (57-59).

Source: Loytved (2009) 